\title{
Striatal Medium Spiny Neurons Terminate in a Distinct Region in the Lateral Hypothalamic Area and Do Not Directly Innervate Orexin/Hypocretin- or Melanin- Concentrating Hormone-Containing Neurons
}

\author{
Hiromi Sano and Mineto Yokoi \\ Molecular Neurogenetics Unit, Horizontal Medical Research Organization, Kyoto University Graduate School of Medicine, Kyoto 606-8501, Japan, and Core \\ Research for Evolutional Science and Technology, Japan Science and Technology Agency, Kawaguchi, 332-0012 Japan
}

\begin{abstract}
Neuronal circuits including medium spiny neurons (MSNs) in the nucleus accumbens (NAc) and melanin-concentrating hormone $(\mathrm{MCH})$-containing neurons in the lateral hypothalamic area (LHA) are hypothesized to play an important role in hedonic feeding. A reciprocal connection between NAc MSNs and $\mathrm{MCH}$-containing neurons is proposed to form a neuronal circuit that is involved in hedonic feeding. Although NAc MSNs have been shown to receive projection from MCH-containing neurons, it is not known whether MCHcontaining neurons in the LHA also receive direct inputs from NAc MSNs. Here, we developed a genetic approach that allows us to visualize almost all striatal MSNs including NAc MSNs. We demonstrate that striatal MSNs terminate in a distinct region within the anterior LHA, and that the terminal area of striatal MSNs in this region contains glutamatergic neurons and is distinctly separate from orexin/hypocretin- or MCH-containing neurons. These observations suggest that NAc MSNs do not directly innervate MCH-containing neurons, but may indirectly signal MCH-containing neurons via glutamatergic neurons in the anterior LHA.
\end{abstract}

Key words: striatal medium spiny neurons; axon terminals; lateral hypothalamic area; melanin-concentrating hormone; hedonic feeding; transgenic mice

\section{Introduction}

Hypothalamic pathways that include the lateral hypothalamic area (LHA) have been shown to regulate homeostatic signals in feeding. In particular, it has been reported that melaninconcentrating hormone $(\mathrm{MCH})$-containing neurons in the LHA are involved in control of food intake and orexin/hypocretincontaining neurons in the LHA likely play a key role in arousal functions related to, or required for feeding (Elmquist et al., 1999; Saper et al., 2002; Saper, 2006).

The LHA is a large and heterogeneous area in the lateral zone of the hypothalamus, which appears to lack clearly definable cell groups and is traversed by the medial forebrain bundle (Berthoud, 2002). Although specific criteria for the subdivision

\footnotetext{
Received Feb. 5, 2007; revised May 15, 2007; accepted May 21, 2007.

This work was supported by the Special Coordination Funds for Promoting Science and Technology from the Ministry of Education, Culture, Sports, Science and Technology of Japan and Core Research for Evolutional Science and Technology from the Japan Science and Technology Agency. The generation of PDE10A2-tTA knock-in mice and bitet0-GFP transgenic mice was conducted in the laboratory of Richard Axel, and we are grateful for his support. We thank M. Mendelsohn, A. Nemes, and T. Suzuki for the generation of the mice used in this study, G. Miesenbock for an ecliptic synaptopHluorin, Y. Date and M. Nakazato for anti-orexin-A and anti-orexin-B antibodies, Y. Nagai for her excellent technical assistance, Y. Kaziro for continuous encouragement, and S. C. Rohani-Montez for careful reading of this manuscript.

Correspondence should be addressed to Mineto Yokoi, Molecular Neurogenetics Unit, Horizontal Medical Research Organization, Kyoto University Graduate School of Medicine, Yoshida-Konoe, Sakyo, Kyoto 606-8501, Japan. E-mail:my151@mac.com.

DOI:10.1523/JNEUROSCI.0514-07.2007

Copyright $\odot 2007$ Society for Neuroscience $\quad$ 0270-6474/07/276948-08\$15.00/0
}

of the LHA have not been defined, this region may be divided into three rostrocaudal subregions that correspond to the anterior, tuberal, and posterior levels of the hypothalamus (Simerly, 2004).

Feeding behavior is strongly influenced by hedonic factors, although it is primarily regulated by homeostatic mechanisms which modulate food intake and energy expenditure resulting in a balance between the two. Clearly, hedonic factors can drive the motivation for food via reward pathways in the brain. The nucleus accumbens (NAc) is a striatal region implicated in natural reward processes and regulation of feeding behaviors (Stratford and Kelley, 1997; Reynolds and Berridge, 2001). Reciprocal interactions between neurons in the NAc and LHA are hypothesized to regulate hedonic feeding (Saper et al., 2002), but an anatomical basis for this interaction remains unclear. $\mathrm{MCH}$-containing neurons in the LHA send efferents to the NAc (Bittencourt et al., 1992). The MCH receptor is strongly expressed in the NAc (Saito et al., 2001). Direct delivery of an MCH1R receptor antagonist to the NAc has been shown to inhibit feeding, whereas intra-NAc injection of MCH stimulated feeding (Georgescu et al., 2005). Thus, neuronal inputs from $\mathrm{MCH}$-containing neurons to the NAc may mediate a motivational component influencing the hedonic aspect of eating (Borowsky et al., 2002). Furthermore, it has been hypothesized that $\mathrm{MCH}$-containing neurons may participate in a self-reinforcing feedback loop that can support feeding by receiving inputs from the NAc (Saper et al., 2002). Although the LHA has been reported to receive axonal projections from 
NAc projection neurons (Mogenson et al., 1983; Heimer et al., 1991; Kirouac and Ganguly, 1995), it is not known whether $\mathrm{MCH}$-containing neurons in the LHA receive direct inputs from the NAc.

Here we show, via genetic visualization of striatal medium spiny neurons (MSNs), that a distinct region in the anterior part of the LHA receives striatal MSN projections. We suggest that GABAergic MSNs from the NAc make synaptic contacts mainly with glutamatergic neurons in a restricted area in the anterior LHA. Moreover, we found that this MSN terminal area in the anterior LHA is distinctly separate from orexin/hypocretin- or $\mathrm{MCH}$-containing neurons. These observations suggest that NAc projection neurons do not directly innervate $\mathrm{MCH}$-containing neurons, but may indirectly send signals to these neurons via glutamatergic neurons in the anterior LHA.

\section{Materials and Methods}

Generation of transgenic mice and mice with targeted alleles PDE10A2-tTA knock-in mouse line. PDE10A2-tTA knock-in mice will be described elsewhere. Briefly, tetracycline-controlled transactivator (tTA) was introduced into the PDE10A2 gene locus using homologous recombination in embryonic stem cells. Because phosphodiesterase 10A2 (PDE10A2) is selectively expressed in striatal MSNs, PDE10A2-tTA knock-in mice recapitulate selective expression of tTA in striatal MSNs (Sano et al., 2006, 2007).

BitetO-GFP mouse line. The enhanced green fluorescent protein (EGFP) fragment from pIRES2-EGFP (Clontech, Mountain View, CA) was introduced into a pBI Tet Vector (Clontech) at the EcoRV site of multiple cloning site (MCS) I. An RT8 artificial fusion gene consisting of a placental alkaline phosphatase fragment, tetanus toxin $\mathrm{C}$ fragment, tyrosine phosphatase $\delta$ fragment, and glutamate receptor 2 fragment was also introduced in the opposite direction in MCS II. The resulting construct, bitet $O-G F P$, contained the bidirectional tetracycline operator (tetO) promoter driving EGFP and a rabbit $\beta$-globin intron/polyadenylation signal in one direction, and in the opposite direction, driving an artificial intron, RT8 and an SV40 polyadenylation signal. A DNA fragment containing bitetO-GFP was excised from the vector by digestion at insert-flanking $A s c I$ sites, gel purified, and microinjected into the pronuclei of fertilized eggs to generate bitet $O-G F P$ transgenic mice. Although both EGFP and RT8 were expected to be transcribed from the bidirectional tetO promoter depending on tTA expression (Baron et al., 1995; Krestel et al., 2001), EGFP was robustly expressed only in transgenic mice bearing this construct in the presence of tTA. The genotype of the animals was determined by PCR of tail genomic DNA with primers unique to the transgene (5'-GATATCTAGAAAACGCAGAAGC, 5' -CCCTAA ATTTTAACACTCTCGATGCC).

TetO-synaptopHluorin mouse line. A DNA fragment containing the tetO promoter (Gossen and Bujard, 1992) followed by an ecliptic synaptopHluorin (kindly gifted by Dr. Miesenbock, Yale University, New Haven, CT) (Miesenbock et al., 1998) and a rabbit $\beta$-globin intron/ polyadenylation signal was excised from the vector by digestion at insertflanking AscI sites, gel purified, and microinjected into the pronuclei of fertilized eggs from C57BL/6CrSlc mice (provided by Japan SLC, Hamamatsu, Japan) to generate tetO-synaptopHluorin transgenic mice, as described previously (Nagai et al., 2005). The genotype of the animals was determined by PCR of tail genomic DNA with primers unique to the transgene (5'-CTTTTCACTGGAGTTGTCCCAATTC, 5' -CCAAT TTGTGTCCAAGAATGTTTCC). Two founder animals were obtained, carrying the tetO-synaptopHluorin transgene. When mated with mice expressing the tTA protein, one line (line $\mathrm{C}$ ) produced offspring in which a strong and specific green fluorescence was detected in tTA-expressing cells; therefore, this line was used for visualization of axon terminals in this study.

The junctions of the constructing process were verified by DNA sequencing. All of the mice used in this study were maintained in strict accordance with institutional animal care guidelines.
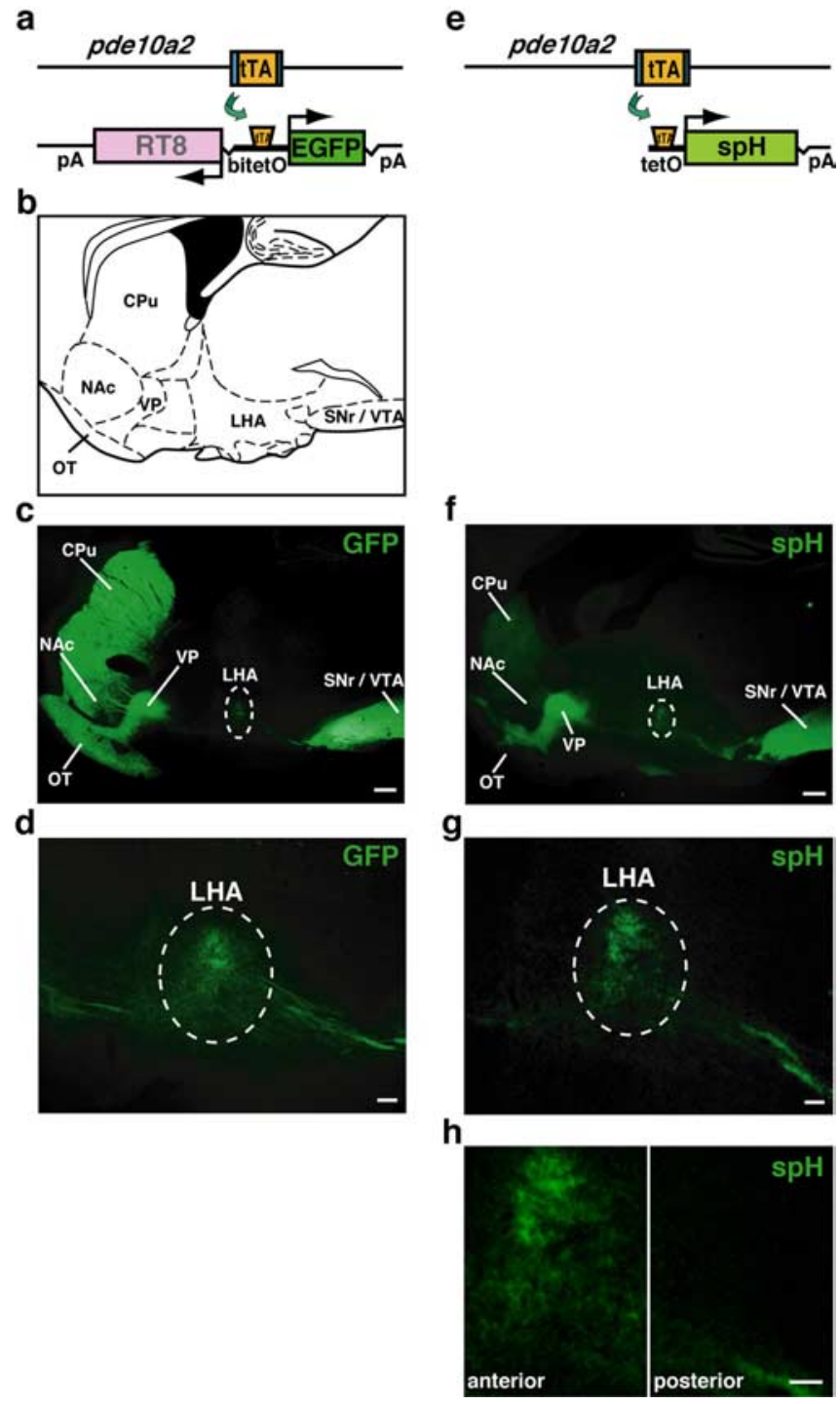

Figure 1. Genetic visualization of striatal MSNs. $\boldsymbol{a}$, Schematic illustration of the induced expression of EGFP in striatal MSNs of PDE10A2-TTA/bitetO-GFP mice. $\boldsymbol{b}$, Illustration of the brain atlas at the similar level of $c$ and $f$. $c$, A representative parasagittal section of the PDE10A2-tTA/bitet0-GFP mouse brain visualized with green fluorescence. $d$, Enlargement of the LHA region in c.e, Schematic illustration of the induced expression of synaptopHluorin (spH) in striatal MSNs of PDE10A2-tTA/tet0synaptopHluorin mice. $\boldsymbol{f}$, A representative parasagittal section of the PDE10A2-tTA/tet0synaptopHlluorin mouse brain visualized with green fluorescence. $\boldsymbol{g}$, Enlargement of the LHA region in $\boldsymbol{f}$. A distinct green fluorescent dense plexus is seen in a restricted region in the anterior LHA (dotted circle; $\boldsymbol{c}, \boldsymbol{d}, \boldsymbol{f}, \boldsymbol{g}) . \boldsymbol{h}, A$ comparison between the anterior LHA region (left) and the posterior LHA region (right) of the PDE10A2-tTA/tet0-synaptopHlluorin mouse brain in higher magnification. Green fluorescent plexus is much more clearly observed in the anterior LHA region than in the posterior $L$ HA region. Scale bars: $\boldsymbol{c}, \boldsymbol{f}, 300 \mu \mathrm{m} ; \boldsymbol{d}, \boldsymbol{g}, \boldsymbol{h}, 100 \mu \mathrm{m}$.

\section{Tracer injection}

Mice were deeply anesthetized with sodium pentobarbital $(50 \mathrm{mg} / \mathrm{kg}$, i.p.) and placed in a stereotaxic apparatus (Narishige, Tokyo, Japan). The scalp was exposed and the bregma was identified. A retrograde tracer was injected at coordinates according to an atlas of the mouse brain (Paxinos and Franklin, 2001). For the anterior LHA, the anteroposterior, mediolateral, and dorsoventral coordinates from the bregma were $-0.50,1.20$, and $4.75 \mathrm{~mm}$, respectively. For the posterior LHA, the anteroposterior, mediolateral, and dorsoventral coordinates from the bregma were $-1.60,1.20$, and $5.00 \mathrm{~mm}$, respectively. The FluoSpheres [carboxylatemodified microspheres, $0.02 \mu \mathrm{m}$, red fluorescent (580/605)] solution (lot 69B1-2; Invitrogen, Eugene, OR) was freshly prepared (4\% solution in saline) and was pressure-injected through a glass micropipette (diam- 
eter, $80-100 \mu \mathrm{m})$. Injection was performed at a constant flow rate of $0.1 \mu \mathrm{l} / \mathrm{min}$ (for the anterior LHA) or $0.2 \mu \mathrm{l} / \mathrm{min}$ (for the posterior LHA) for 5 min with a microinfusion pump connected to the glass micropipette. Three days after injection, the mice were perfused transcardially with $4 \%$ paraformaldehyde (PFA) in 0.1 $\mathrm{M}$ phosphate buffer (PB). Their brains were removed, postfixed in $4 \% \mathrm{PFA}$ at $4^{\circ} \mathrm{C}$ overnight, and cryoprotected in $30 \%$ sucrose in $0.1 \mathrm{M} \mathrm{PB}$ at $4^{\circ} \mathrm{C}$. The brains were then cryosectioned in 30 $\mu \mathrm{m}$ parasagittal sections and collected in $0.01 \mathrm{M}$ PBS. The brain sections were mounted on 3-aminopropyltriethoxy silane (APS)-coated slides (Matsunami, Osaka, Japan), air-dried, and coverslipped. In the experiments to inject the tracer into the anterior LHA, injection sites in which the tracer did not target any part of the green fluorescent region in the anterior LHA served as negative controls.

\section{Immunohistochemistry, fluorescent Nissl staining, and microscopy}

Histology and immunohistochemistry were performed on $>8$-week-old mice. Mice were perfused transcardially with PBS and 4\% PFA in $0.1 \mathrm{M}$ PB. Brains were removed, postfixed (overnight), and cryoprotected (in 30\% sucrose). The tissue was then frozen in OCT compound (Tissue-Tek; Sakura, Tokyo, Japan), and 30-40 $\mu \mathrm{m}$ parasagittal or coronal sections were cut on a cryostat. Sections were treated according to standard histochemistry protocols, as described previously (Nagai et al., 2005). Primary antibodies against vesicular GABA transporter (VGAT) (1:2000; Millipore, Temecula, CA), gephyrin (1:300; Synaptic Systems, Goettingen, Germany), $\mathrm{MCH}$ (1:3000; Millipore), and orexin-A, and -B (1:20000; kindly gifted from Dr. Date, University of Miyazaki, Kiyotake, Japan) (Date et al., 1999) were used, incubated at $4^{\circ} \mathrm{C}$ overnight. Subsequently, Cy3-conjugated secondary antibodies against goat (Jackson Immunoresearch, West Grove, PA) were applied at 1:500 dilution for $1-2 \mathrm{~h}$ at room temperature. Nissl staining was performed by incubating brain sections with red fluorescent Nissl staining solution (1:100; Invitrogen,). TOTO-3 (1 $\mu \mathrm{m}$; Invitrogen) was used for counterstaining. Brain sections and whole brains were visualized and images were acquired using a Zeiss (Oberkochen, Germany) LSM510 confocal microscope, a Zeiss Axio Imager.M1, or a Leica (Nussloch, Germany) MZ16F microscope with an Olympus (Tokyo, Japan) DP70 digital camera. The following microscope filters for florescence were used: BP505-530 for EGFP and synaptopHluorin, BP560-615 or LP560 for Cy3 and FluoSpheres, and LP650 for TOTO-3.

\section{In situ hybridization}

Probes for in situ hybridization with vesicular glutamate transporter 2 (VGLUT2) (GenBank accession number AF324864, 934-1893 bp fragment) and glutamic acid decarboxylase 67 (Gad67) (GenBank accession number NM_008077, 281-821 bp fragment) were prepared by in vitro transcription with digoxigenin-labeled UTP (Roche, Tokyo, Japan). Mice were perfused transcardially with $4 \%$ PFA in $0.1 \mathrm{M} \mathrm{PB}$ and the brains were removed, postfixed with $4 \% \mathrm{PFA}$ in $0.1 \mathrm{M} \mathrm{PB}$ at $4^{\circ} \mathrm{C}$ overnight, followed by cryoprotection with $30 \%$ sucrose in $0.1 \mathrm{M} \mathrm{PB}$ at $4^{\circ} \mathrm{C}$. The brains were cryosectioned in $14 \mu \mathrm{m}$ parasagittal sections and dried onto APS-coated slides (Matsunami). The sections were then fixed with $4 \%$ PFA in $0.1 \mathrm{M}$ PB for $10 \mathrm{~min}$, washed twice with PBS, incubated in $0.1 \mathrm{M}$ triethanolamine containing $0.25 \%$ acetic anhydride for $10 \mathrm{~min}$, and air dried. Prehybridization was performed at $70^{\circ} \mathrm{C}$ for $1 \mathrm{~h}$ with prehybrid- ization buffer $(50 \%$ formamide, $5 \times$ SSC, $1 \times$ Denhard's solution, $0.1 \%$ Tween 20, $250 \mathrm{mg} / \mathrm{ml}$ HRE $600 \mathrm{tRNA}$, and $500 \mathrm{mg} / \mathrm{ml}$ herring sperm DNA). Hybridization was performed at $70^{\circ} \mathrm{C}$ overnight with hybridization buffer $(50 \%$ formamide, $5 \times$ SSC, $1 \times$ Denhard's solution, $0.1 \%$ Tween 20, $250 \mathrm{mg} / \mathrm{ml}$ HRE 600 tRNA, $500 \mathrm{mg} / \mathrm{ml}$ herring sperm DNA, and $500 \mathrm{ng} / \mathrm{ml}$ RNA probe). After hybridization, sections were washed with $5 \times \mathrm{SSC}$ at $65^{\circ} \mathrm{C}$ for $10 \mathrm{~min}$ and $0.2 \times \mathrm{SSC}$ at $65^{\circ} \mathrm{C}$ for $30 \mathrm{~min}$ four times. Sections were equilibrated with buffer $1(100 \mathrm{~mm}$ Tris- $\mathrm{HCl}$ and $150 \mathrm{~mm} \mathrm{NaCl}, \mathrm{pH} 7.5)$ and subsequently incubated in buffer $2(10 \%$ sheep serum in buffer 1) for $1 \mathrm{~h}$ and, finally, incubated with antidigoxigenin-AP Fab fragments in buffer 2 (1:4000 dilution; Roche) at $4^{\circ} \mathrm{C}$ overnight. Sections were then washed in buffer 1 for $15 \mathrm{~min}$ four times, equilibrated in buffer 3 (100 mM Tris- $\mathrm{HCl}, 100 \mathrm{~mm} \mathrm{NaCl}$ and 50 $\mathrm{mm} \mathrm{MgCl}_{2}, \mathrm{pH}$ 9.5), and developed in the dark in buffer 3 containing 4-nitro blue tetrazolium chloride/5-bromo-4-chloro-3-indolylphosphate (Roche). Development was stopped by washing sections with PBS. These were then mounted using AquaPoly/Mount (Polysciences, Warrington, PA).

\section{Results}

Genetic visualization of striatal medium spiny neurons

To genetically visualize striatal MSNs [the projection neurons of the striatal complex including the caudate-putamen $(\mathrm{CPu})$, the 
a

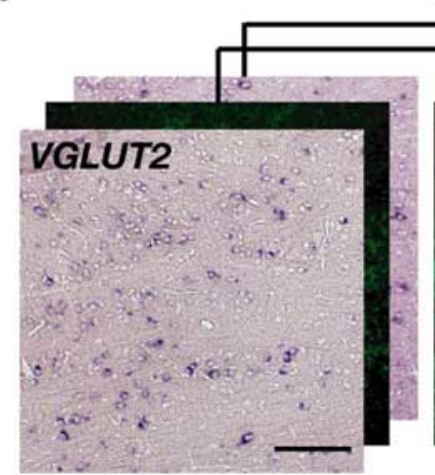

b

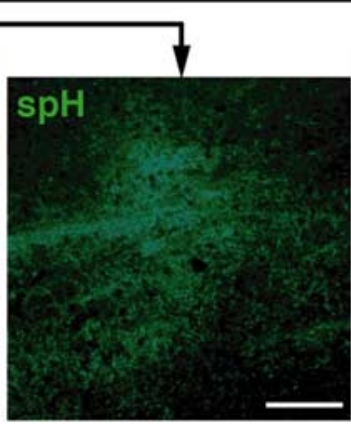

d

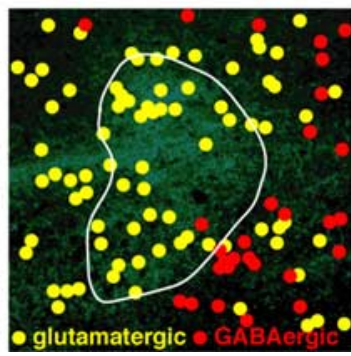

C

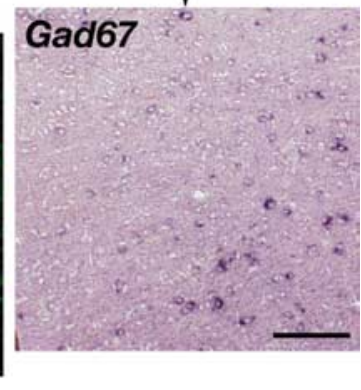

mouse line bearing the tetO-synaptopHluorin transgene. SynaptopHluorin is a $\mathrm{pH}$-sensitive mutant of green fluorescent protein predominantly sorted to synaptic vesicles in axon terminals (Miesenbock et al., 1998). We obtained two tetO-synaptopHluorin transgenic mouse lines, and mated them with PDE10A2-tTA knock-in mice (Fig. 1e). When brains of the offspring from this cross were analyzed, we observed fluorescently labeled substantia nigra in only one of the lines. Hereafter, we have used this particular fluorescent PDE10A2-tTA/tetOsynaptopHluorin compound mouse line for additional analyses. The intensity of green fluorescence detected in PDE10A2tTA/tetO-synaptopHluorin compound mice was much stronger in the axon terminal fields than that in the somatodendritic fields (Fig. 1f), whereas PDE10A2-tTA/ bitetO-GFP compound mice showed green fluorescence almost equally in the somatodendritic and axon terminal fields (Fig. 1c). Therefore, by using PDE10A2tTA/tetO-synaptopHluorin compound mice, we undoubtedly visualized the axon terminal fields of striatal MSNs with green fluorescence, resulting in clearly obtaining the fluorescent image of the dense plexus in a restricted region of the anterior LHA, which seems to comprise the likely axon terminals of striatal MSNs (Fig. $1 f-h$ ).

nucleus accumbens (NAc) and the olfactory tubercle (OT)], we took advantage of our bitransgenic system, that is, the tTA/tetO system, in mice. As tTA driver mice, we used the PDE10A2-tTA line, in which tTA appears to be selectively expressed in all striatal MSNs in the brain (Sano et al., 2006, 2007). In this way, gene expression could be driven by the tetO promoter in the tTA expressing striatal MSNs. As tetO reporter mice, we generated two transgenic mouse lines: a bitet $O-G F P$ mouse line and a tet $O$ synaptopHluorin mouse line.

In compound heterozygote mice bearing the PDE10A2-tTA allele and the bitetO-GFP transgene (Fig. 1a), we found strong green fluorescent signals in striatal MSNs comprising their somatodendrites and axons (Fig. $1 c$, supplemental Fig. $1 a, b$, available at www.jneurosci.org as supplemental material). Approximately $90 \%$ of Nissl-stained neurons in the striatal complex of PDE10A2-tTA/bitetO-GFP compound heterozygotes exhibited green fluorescence (supplemental Fig. $1 c$, available at www.jneurosci.org as supplemental material); therefore, we evaluated that almost all striatal MSNs were fluorescently labeled in the PDE10A2-tTA/bitetO-GFP mouse striatum. As such, we were able to analyze the whole projection area of striatal MSNs including the $\mathrm{CPu}$, the NAc, and the OT. The target areas of striatal MSNs, the globus pallidus (GP), substantia nigra pars reticulata/ ventral tegmental area (SNr/VTA), ventral pallidum (VP), subthalamic nucleus, and pedunculopontine tegmental nucleus were clearly visualized by green fluorescence (Fig. $1 c$, supplemental Fig. $1 a, b$, available at www.jneurosci.org as supplemental material). Remarkably, we also detected a distinct region of green fluorescence in the anterior part of the LHA, composed of a diffusely organized dense plexus of fibers (Fig. 1c,d).

To more clearly visualize axon terminal regions, we generated a

\section{Striatal MSNs terminate on neurons in a distinct region in the anterior LHA}

Although a diffusely scattered fiber pattern rather than a fascicular bundled pattern is suggestive of preterminal fibers and terminals (Heimer et al., 1991), we next sought to confirm that the dense plexus visualized in the anterior LHA did indeed consist of axon terminals not en route of striatal MSNs. Striatal MSNs are GABAergic neurons (Wilson, 2004), which express VGAT at high concentrations in their nerve endings (Chaudhry et al., 1998). We were therefore able to use VGAT as a molecular marker for axon terminals of striatal MSNs. We performed immunostaining against VGAT on the PDE10A2-tTA/tetO-synaptopHluorin brain sections, and unambiguously observed colocalization of GFP fluorescence with VGAT immunostaining in the anterior LHA similar to staining patterns observed in the GP and the SNr (Fig. $2 a$, supplemental Fig. $2 a, b$, available at www.jneurosci.org as supplemental material). These data demonstrate that the green fluorescent plexus in the anterior LHA of the PDE10A2-tTA/tetOsynaptopHluorin mouse brain contains the GABAergic axon terminals of striatal MSNs.

We next performed fluorescent Nissl staining on the brain sections of PDE10A2-tTA/tetO-synaptopHluorin mice and found that neurons were encircled within the green fluorescent plexus in the anterior LHA (supplemental Fig. $2 c$, available at www. jneurosci.org as supplemental material).

Furthermore, because gephyrin is one of the postsynaptic molecules for GABAergic synaptic transmission and can be used as a molecular marker for the GABAergic postsynaptic sites (Sassoe-Pognetto et al., 2000), we performed immunostaining against gephyrin on the brain sections of PDE10A2-tTA/tetO- 
synaptopHluorin mice. We found that the gephyrin immunoreactivity was located in the neurons encircled with the green fluorescent axons of GABAergic striatal MSNs in the anterior LHA of the PDE10A2-tTA/ tetO-synaptopHluorin mouse brains (Fig. $2 b$ ). Thus, our findings suggest that the axons of GABAergic striatal MSNs terminate and make synaptic contacts with neurons in the restricted area of the anterior LHA.

\section{MSNs in the NAc project to the} anterior LHA

We next asked which axons of striatal MSNs of the CPu, the NAc, or the OT terminate within the distinct area in the anterior LHA described above. To attempt to answer this question, we injected a retrograde tracer into the green fluorescent region in the anterior LHA of PDE10A2tTA/bitetO-GFP mouse brains using a stereotaxic apparatus. We chose redfluorescent microspheres as the retrograde tracer because of their minimal diffusion from the injection site (Katz et al., 1984). Although we were not able to inject the tracer into the whole area of the green fluorescent LHA region, we successfully injected the tracer into several places within the green fluorescent MSN terminal region in the anterior LHA (Fig. 2c). We clearly detected red fluorescent signals of the tracer in the cell bodies of MSNs labeled with GFP fluorescence, allowing us to locate the somata of the neurons importing the tracer (Fig. 2c). Although we detected no MSNs with red signals in the OT and only a few MSNs with red signals in the $\mathrm{CPu}$ (data not shown), the majority of MSNs labeled with the red microspheres were located in the NAc (Fig. 2c). Thus, the anterior LHA is one of the sites directly innervated by NAc GABAergic neurons. However, the population size of GABAergic neurons that reside in the NAc and target the anterior LHA remains unknown.

\section{Terminal area of striatal MSNs in the anterior LHA contains} glutamatergic neurons

To characterize the postsynaptic neurons that possibly make synaptic contacts with GABAergic striatal MSNs in the anterior LHA, we asked whether glutamatergic and/or GABAergic neurons reside in this area. Using VGLUT2 or Gad67 cRNA probes as glutamatergic or GABAergic neuronal markers, respectively (Lu et al., 2006), we performed in situ hybridization against serial brain sections including the GFP fluorescently labeled LHA area of PDE10A2-tTA/tetO-synaptopHluorin compound mice. We detected neurons containing VGLUT2 mRNA, but not Gad67 mRNA, almost exclusively within the green fluorescent plexus in the anterior LHA (Fig. 3). These findings suggest that GABAergic striatal MSNs can form synapses with glutamatergic neurons in this distinct region in the anterior LHA.

\section{The terminal area of striatal MSNs in the LHA does not} colocalize with $\mathrm{MCH}$ - or orexin/hypocretin-containing neurons To further characterize the terminal region of striatal MSNs in the LHA, we next asked whether $\mathrm{MCH}$-containing neurons and/or orexin/hypocretin-containing neurons reside in this area and whether they synapse with the striatal MSN axon terminals. We performed immunostaining using an anti-MCH antibody in the LHA of PDE10A2-tTA/bitetO-GFP compound mice and showed that the green fluorescent dense plexus in the anterior LHA is distinctly separate from $\mathrm{MCH}$-containing neurons, which were distributed at least $100 \mu \mathrm{m}$ posterior to the green fluorescent plexus (Fig. 4a). Because lateral hypothalamic neurons typically spread their dendrites perpendicularly to the longitudinally running axons of the medial forebrain bundle (Millhouse, 1979), our data suggest that the axons of striatal MSNs including NAc MSNs would not make synaptic contacts with MCH-containing neurons.

We also determined the localization of orexin/hypocretincontaining neurons in the LHA by immunostaining with antiorexin-A and anti-orexin-B antibodies on PDE10A2-tTA/bitetOGFP brain sections, and found that these neurons are also distinctly separate from the green fluorescent plexus regions (Fig. $4 b$ ). This suggests, similarly to $\mathrm{MCH}$-containing neurons, that striatal MSNs including NAc MSNs do not directly project to orexin/hypocretin-containing neurons in the LHA.

\section{Neuronal connections from the striatal MSN terminal region} in the anterior LHA to the posterior LHA

Finally, we asked whether neurons within the striatal MSN terminal region in the anterior LHA send axons to the posterior LHA where $\mathrm{MCH}$ - or orexin/hypocretin-containing neurons are located. We injected a retrograde tracer into the posterior LHA of PDE10A2-tTA/bitetO-GFP mouse brains (Fig. 5a) and detected 
a

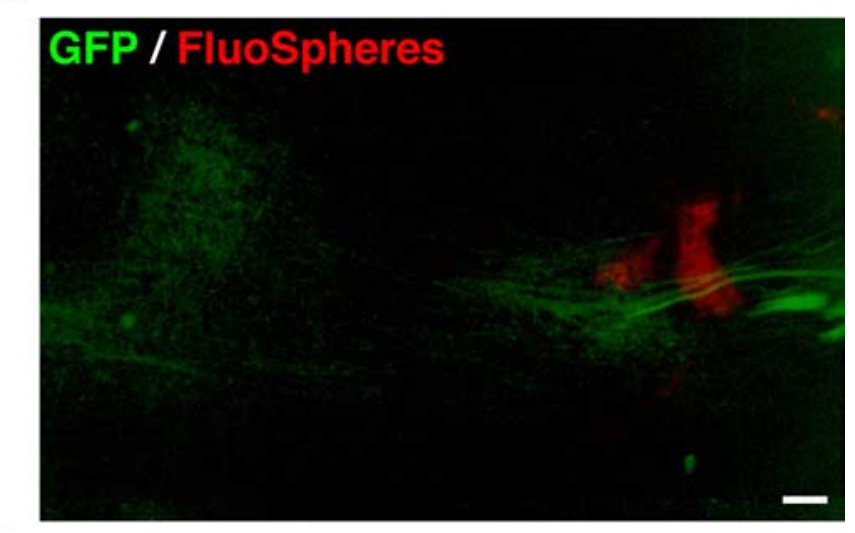

b

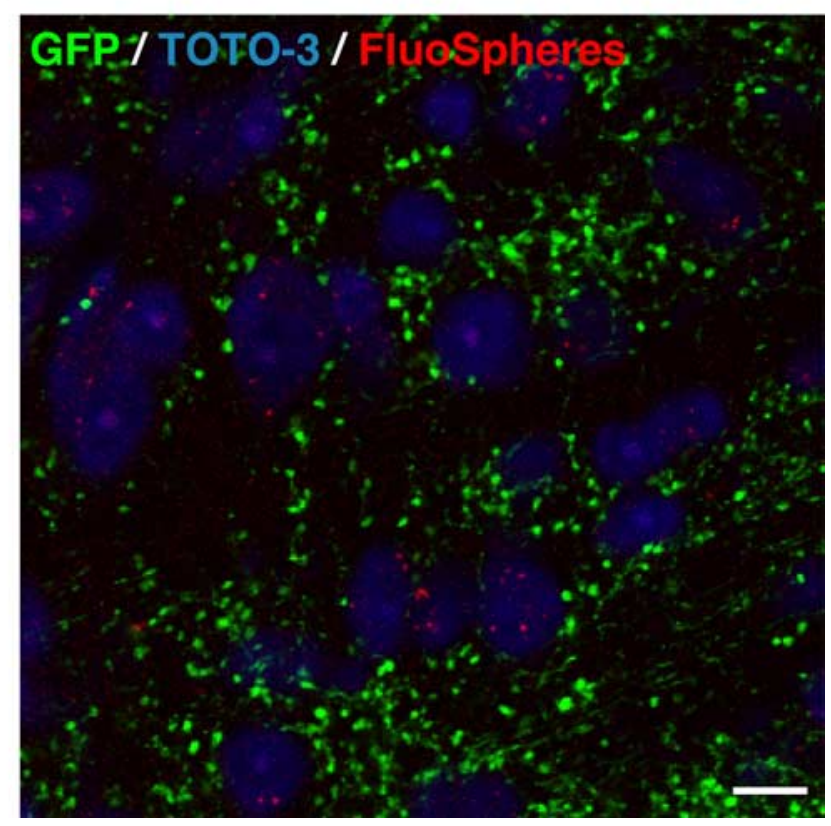

Figure 5. $\boldsymbol{a}, \boldsymbol{b}$, Retrograde tracer FluoSpheres (red) placed within the posterior LHA of GFPexpressing mice (PDE10A2-tTA/bitet0-GFP) (a) were transported to cell bodies of neurons that reside in the green fluorescent plexus in the anterior LHA $(\boldsymbol{b})$. Sections were counterstained with TOT0-3 (blue). Scale bars: $\boldsymbol{a}, 100 \mu \mathrm{m} ; \boldsymbol{b}, 10 \mu \mathrm{m}$.

red fluorescent signals of the tracer in cell bodies within the green fluorescent plexus in the anterior LHA (Fig. 5b). In addition, we did not detect the red fluorescent signals of the tracer in the NAc, although we observed many cortical cells with red fluorescent signals. Although these results should be interpreted with caution because of the possibility of tracer uptake by fibers of passage, our observations suggest that neurons residing in the striatal MSN terminal region in the anterior LHA project to the posterior region of the LHA where $\mathrm{MCH}$-containing neurons reside.

\section{Discussion}

In the present study, by using transgenic mice that inducibly express either GFP or synaptopHluorin in striatal MSNs, we have visualized and characterized the projection region of striatal MSNs in the LHA. We demonstrate that within the LHA, a large heterogeneous area in the lateral zone of the hypothalamus that has not been intensively characterized, a small, distinct region in the anterior part receives projections from the striatal complex. Furthermore, we suggested that NAc MSNs form synaptic con- tacts with glutamatergic neurons in this region, which do not express either orexins/hypocretins or MCH. Our results, thus, would exclude the neuronal circuit of direct inputs from the NAc to $\mathrm{MCH}$-containing neurons, which has been proposed previously (Saper et al., 2002).

PDE10A2 is a PDE10A splice variant (Hu et al., 2004), which is selectively expressed in striatal MSNs in the mouse brain (Sano et al., 2006, 2007). Therefore, by knocking in tTA into the PDE10A2 gene locus, selective distribution of tTA in striatal MSNs was achieved in a manner that recapitulates expression of PDE10A2 (Sano et al., 2007). Because inducible expression using the tetracycline transactivator system has been successfully used in mice (Mayford et al., 1996; Yu et al., 2004; Sano et al., 2007), we were able to take advantage of this system to express our transgene driven by the tetO promoter in striatal MSNs when crossed with PDE10A2-tTA knock-in mice. Using this tTA strategy, we have demonstrated here that either GFP or synaptopHluorin was expressed in striatal MSNs.

As a modified version of tetO promoter, the bidirectional tetO promoter has been used to drive expression of two transcripts from a single transgene in several transgenic mouse lines (Yamamoto et al., 2000; Krestel et al., 2001). In the bitetO-GFP mouse line, however, only unidirectional expression of GFP was observed. It is possible that this occurred because of genomic integration at a locus in which one strand of the transgene DNA is preferentially transcribed; alternatively, artificial RT8 transcripts might be unstable in vivo.

Interactions between the LHA and the NAc have been proposed to play a prominent role in hedonic eating (Stratford and Kelley, 1999; Saper et al., 2002, Kelley et al., 2005); however, the details of these interactions are not well understood. Even the neural circuit between the NAc and the LHA has been elusive. Previous anterograde tracing studies have shown that NAc MSNs send axons to the LHA and have suggested that NAc projections terminate throughout the rostrocaudal extent of the LHA (Heimer et al., 1991; Kirouac and Ganguly, 1995). In addition, electrophysiological studies have shown that single pulse stimulation of the NAc elicits inhibitory or excitatory responses in the LHA (Mogenson et al., 1983). However, until now it has been unclear whether NAc projections terminate diffusely and widely or in a restricted and distinct region of the LHA. The present study demonstrated, for the first time to our knowledge, by using genetic visualization of axon terminals of striatal MSNs combined with histochemical analyses, that striatal MSNs including NAc MSNs do, in fact, terminate in a distinct region of the LHA. This target region of striatal MSNs in the LHA was unexpectedly restricted and located within an, as of yet, uncharacterized area in the anterior part of the LHA.

The neuronal elements and the nature of the neuronal circuits in the anterior LHA are not well characterized as of yet. By taking advantage of robust genetic visualization as described here, we can now start to characterize this striatal MSN terminal region in the anterior LHA. Our results have shown that many glutamatergic neurons versus only a few GABAergic neurons are distributed within the striatal MSN terminal region of the LHA, suggesting that signals from the NAc may be transmitted to glutamatergic neurons in the anterior LHA.

$\mathrm{MCH}$-containing neurons are mainly distributed in the LHA, and a reciprocal connection between the NAc and $\mathrm{MCH}$ containing neurons has been postulated to be an important neuronal circuit for hedonic feeding behavior (Saper et al., 2002). It has been demonstrated that $\mathrm{MCH}$-containing neurons do send axons to NAc MSNs (Bittencourt et al., 1992), but whether NAc 
MSNs send axons back to MCHcontaining neurons has previously been unknown. Our results have demonstrated that the terminal area of NAc MSNs is distinctly separate from $\mathrm{MCH}$-containing neurons. Because lateral hypothalamic neurons typically spread their dendrites perpendicularly to the longitudinally running axons of the medial forebrain bundle (Millhouse, 1979), our data suggest that the axons of NAc MSNs would not make synaptic connections with $\mathrm{MCH}$ containing neurons, excluding a direct reciprocal connection between the NAc and $\mathrm{MCH}$-containing neurons.

Because it is likely that NAc MSNs do not directly convey signals that induce hedonic feeding behavior to $\mathrm{MCH}-$ containing neurons, what neuronal elements could be responsible for relaying this information from the NAc to $\mathrm{MCH}$-containing neurons? We found that neurons in the NAc project to the anterior LHA and that $\mathrm{MCH}$-containing neurons are distributed in the tuberal and posterior LHA. We also demonstrated that terminal area of striatal MSNs in the anterior LHA contains glutamatergic neurons (Fig. 3), and that there appear to be neuronal connections from the striatal MSN terminal region in the anterior LHA to the posterior LHA (Fig. 5). Previous studies have shown that excitatory synaptic input to $\mathrm{MCH}$-containing neurons is a result of glutamate release (van den Pol et al., 2004), and inputs from MCHcontaining neurons to neurons in the NAc have been believed to be inhibitory (Elias et al., 2001; Gao and van den Pol, 2001). Based on our findings and these reports, we propose a neuronal circuit model to describe the pathways involved in hedonic feeding (Fig. 6). In this model, MSNs in the NAc send GABAergic inhibitory efferents to the anterior LHA glutamatergic neurons, which then send excitatory efferents to $\mathrm{MCH}$-containing neurons. These, in turn, send inhibitory efferents back to NAc MSNs to complete the circuit. Thus, once neuronal inputs from $\mathrm{MCH}-$ containing neurons are received in the NAc, NAc MSNs would be inhibited, the anterior LHA neurons would then be disinhibited, and finally, $\mathrm{MCH}$-containing neurons would be excited, resulting in continuous activation of $\mathrm{MCH}$-containing neurons. If it is this continuous activation of $\mathrm{MCH}$-containing neurons which elicits hedonic feeding, then this model may shed light on a neuronal basis for hedonic feeding. Previous pharmacobehavioral findings support this proposed neuronal circuit model. For example, intra-NAc injection of the MCH1R receptor antagonist has been shown to inhibit feeding (Georgescu et al., 2005); infusion of the $\mathrm{GABA}_{\mathrm{A}}$ agonist into the anterior part of the LHA has been shown to inhibit the feeding response induced by inhibition of neurons in the NAc (Maldonado-Irizarry et al., 1995). Finally, a glutamatergic antagonist infused in the posterior part of the LHA was shown to block the hyperphagia induced by GABAergic stimulation of the NAc neurons (Stratford and Kelley, 1999). To evaluate our model, additional neuroanatomical analyses will be required. For example, a transsynaptic retrograde genetic tracer (Maskos et al., 2002; Sano et al., 2007) can be introduced into $\mathrm{MCH}$-containing neurons using a viral vector (van den Pol et al., 2004) or via transgenic animals. Behavioral studies should also be conducted to test whether hedonic feeding is affected when the proposed neuronal circuits are manipulated.

In addition to being involved in ingestive behavior, the lateral zone of the hypothalamus has been implicated in the processing of sensory information, arousal state, and the expression of behaviors associated with aggression and reproduction (Simerly, 2004). It is possible, therefore, that the plexus area in the LHA visualized as the terminal region of striatal MSNs in our transgenic mice might also be involved in regulating these behaviors. The characterization of this terminal area described in this study provides some insight into the anatomy of the LHA and the transgenic mouse lines described here may serve as genetic tools for additional studies.

\section{References}

Baron U, Freundlieb S, Gossen M, Bujard H (1995) Co-regulation of two gene activities by tetracycline via a bidirectional promoter. Nucleic Acids Res 23:3605-3606.

Berthoud HR (2002) Multiple neural systems controlling food intake and body weight. Neurosci Biobehav Rev 26:393-428.

Bittencourt JC, Presse F, Arias C, Peto C, Vaughan J, Nahon JL, Vale W, Sawchenko PE (1992) The melanin-concentrating hormone system of the rat brain: an immuno- and hybridization histochemical characterization. J Comp Neurol 319:218-245.

Borowsky B, Durkin MM, Ogozalek K, Marzabadi MR, DeLeon J, Lagu B, Heurich R, Lichtblau H, Shaposhnik Z, Daniewska I, Blackburn TP, Branchek TA, Gerald C, Vaysse PJ, Forray C (2002) Antidepressant, anxiolytic and anorectic effects of a melanin-concentrating hormone-1 receptor antagonist. Nat Med 8:825-830.

Chaudhry FA, Reimer RJ, Bellocchio EE, Danbolt NC, Osen KK, Edwards RH, Storm-Mathisen J (1998) The vesicular GABA transporter, VGAT, localizes to synaptic vesicles in sets of glycinergic as well as GABAergic neurons. J Neurosci 18:9733-9750.

Date Y, Ueta Y, Yamashita H, Yamaguchi H, Matsukura S, Kangawa K, Sakurai T, Yanagisawa M, Nakazato M (1999) Orexins, orexigenic hypothalamic peptides, interact with autonomic, neuroendocrine and neuroregulatory systems. Proc Natl Acad Sci USA 96:748-753.

Elias CF, Lee CE, Kelly JF, Ahima RS, Kuhar M, Saper CB, Elmquist JK (2001) Characterization of CART neurons in the rat and human hypothalamus. J Comp Neurol 432:1-19.

Elmquist JK, Elias CF, Saper CB (1999) From lesions to leptin: hypothalamic control of food intake and body weight. Neuron 22:221-232.

Gao XB, van den Pol AN (2001) Melanin concentrating hormone depresses synaptic activity of glutamate and GABA neurons from rat lateral hypothalamus. J Physiol (Lond) 533:237-252.

Georgescu D, Sears RM, Hommel JD, Barrot M, Bolanos CA, Marsh DJ, Bednarek MA, Bibb JA, Maratos-Flier E, Nestler EJ, DiLeone RJ (2005) The hypothalamic neuropeptide melanin-concentrating hormone acts in the nucleus accumbens to modulate feeding behavior and forced-swim performance. J Neurosci 25:2933-2940.

Gossen M, Bujard H (1992) Tight control of gene expression in mammalian 
cells by tetracycline-responsive promoters. Proc Natl Acad Sci USA 89:5547-5551.

Heimer L, Zahm DS, Churchill L, Kalivas PW, Wohltmann C (1991) Specificity in the projection patterns of accumbal core and shell in the rat. Neuroscience 41:89-125.

Hu H, McCaw EA, Hebb AL, Gomez GT, Denovan-Wright EM (2004) Mutant huntingtin affects the rate of transcription of striatum-specific isoforms of phosphodiesterase 10A. Eur J Neurosci 20:3351-3363.

Katz LC, Burkhalter A, Dreyer WJ (1984) Fluorescent latex microspheres as a retrograde neuronal marker for in vivo and in vitro studies of visual cortex. Nature 310:498-500.

Kelley AE, Baldo BA, Pratt WE, Will MJ (2005) Corticostriatalhypothalamic circuitry and food motivation: integration of energy, action and reward. Physiol Behav 86:773-795.

Kirouac GJ, Ganguly PK (1995) Topographical organization in the nucleus accumbens of afferents from the basolateral amygdala and efferents to the lateral hypothalamus. Neuroscience 67:625-630.

Krestel HE, Mayford M, Seeburg PH, Sprengel R (2001) A GFP-equipped bidirectional expression module well suited for monitoring tetracyclineregulated gene expression in mouse. Nucleic Acids Res 29:E39.

Lu J, Sherman D, Devor M, Saper CB (2006) A putative flip-flop switch for control of REM sleep. Nature 441:589-594.

Maldonado-Irizarry CS, Swanson CJ, Kelley AE (1995) Glutamate receptors in the nucleus accumbens shell control feeding behavior via the lateral hypothalamus. J Neurosci 15:6779-6788.

Maskos U, Kissa K, St. Cloment C, Brulet P (2002) Retrograde transsynaptic transfer of green fluorescent protein allows the genetic mapping of neuronal circuits in transgenic mice. Proc Natl Acad Sci USA 99:10120-10125.

Mayford M, Bach ME, Huang YY, Wang L, Hawkins RD, Kandel ER (1996) Control of memory formation through regulated expression of a CaMKII transgene. Science 274:1678-1683.

Miesenbock G, De Angelis DA, Rothman JE (1998) Visualizing secretion and synaptic transmission with $\mathrm{pH}$-sensitive green fluorescent proteins. Nature 394:192-195.

Millhouse OE (1979) A Golgi anatomy of the rodent hypothalamus. In: Handbook of the hypothalamus (Morgane PJ, Panksepp J, eds), pp 221265. New York: Dekker.

Mogenson GJ, Swanson LW, Wu M (1983) Neural projections from nucleus accumbens to globus pallidus, substantia innominata, and lateral preoptic-lateral hypothalamic area: an anatomical and electrophysiological investigation in the rat. J Neurosci 3:189-202.
Nagai Y, Sano H, Yokoi M (2005) Transgenic expression of Cre recombinase in mitral/tufted cells of the olfactory bulb. Genesis 43:12-16.

Paxinos G, Franklin KB (2001) The mouse brain in stereotaxic coordinates. San Diego: Academic.

Reynolds SM, Berridge KC (2001) Fear and feeding in the nucleus accumbens shell: rostrocaudal segregation of GABA-elicited defensive behavior versus eating behavior. J Neurosci 21:3261-3270.

Saito Y, Cheng M, Leslie FM, Civelli O (2001) Expression of the melaninconcentrating hormone $(\mathrm{MCH})$ receptor mRNA in the rat brain. J Comp Neurol 435:26-40.

Sano H, Nagai Y, Yokoi M (2006) Phosphodiesterase 10A2 (PDE10A2) regulates social interaction through striatal cAMP signaling. Soc Neurosci Abstr 32:578.12.

Sano H, Nagai Y, Yokoi M (2007) Inducible expression of retrograde transynaptic genetic tracer in mice. Genesis 45:123-128.

Saper CB (2006) Staying awake for dinner: hypothalamic integration of sleep, feeding, and circadian rhythms. Prog Brain Res 153:243-252.

Saper CB, Chou TC, Elmquist JK (2002) The need to feed: homeostatic and hedonic control of eating. Neuron 36:199-211.

Sassoe-Pognetto M, Panzanelli P, Sieghart W, Fritschy JM (2000) Colocalization of multiple $\mathrm{GABA}_{\mathrm{A}}$ receptor subtypes with gephyrin at postsynaptic sites. J Comp Neurol 420:481-498.

Simerly RB (2004) Anatomical substrates of hypothalamic integration. In: The rat nervous system (Paxinos G, ed), pp 335-368. San Diego: Elsevier.

Stratford TR, Kelley AE (1997) GABA in the nucleus accumbens shell participates in the central regulation of feeding behavior. J Neurosci 17:4434-4440.

Stratford TR, Kelley AE (1999) Evidence of a functional relationship between the nucleus accumbens shell and lateral hypothalamus subserving the control of feeding behavior. J Neurosci 19:11040-11048.

van den Pol AN, Acuna-Goycolea C, Clark KR, Ghosh PK (2004) Physiological properties of hypothalamic $\mathrm{MCH}$ neurons identified with selective expression of reporter gene after recombinant virus infection. Neuron 42:635-652.

Wilson CJ (2004) Basal ganglia. In: The synaptic organization of the brain (Shepherd GM, ed), pp361-413. New York: Oxford UP.

Yamamoto A, Lucas JJ, Hen R (2000) Reversal of neuropathology and motor dysfunction in a conditional model of Huntington's disease. Cell 101:57-66.

Yu CR, Power J, Barnea G, O’Donnell S, Brown HE, Osborne J, Axel R, Gogos JA (2004) Spontaneous neural activity is required for the establishment and maintenance of the olfactory sensory map. Neuron 42:553-566. 